\title{
Visión de sí y de otros en adolescentes a partir de la elaboración de memes basados en la lectura de Alicia en el país de las maravillas
}

\author{
Vision of themselves and others in adolescents from the development of memes based on \\ the reading of Alice in Wonderland
}

\author{
Nelly Marina Elizalde \\ e-mail: nellymareli@gmail.com \\ Instituto Tecnológico y de Estudios Superiores de Monterrey. México
}

\section{Resumen}

El presente estudio muestra la percepción de sí mismo y del otro que tiene un grupo de adolescentes de entre 12 y 13 años que viven en la zona urbana de la Ciudad de México y estudian el primer año de secundaria en una escuela privada de clase media y media alta, esto a través de 85 memes realizados con posterioridad a la lectura de Alicia en el país de las maravillas. Se trata de una investigación cuantitativa que arroja como resultados quiénes son las figuras de autoridad y los miedos que tienen los adolescentes en la actualidad, además muestra la cantidad de palabras que necesitan los jóvenes para transmitir una idea completa a través de un meme y sus preocupaciones por los problemas sociales en los que se ven o han visto involucrados. Todo esto se descubre a partir de algún personaje o escena seleccionado por los alumnos mismos después de la lectura de un clásico de la literatura universal asignado en la clase de Español. Este estudio busca mostrar cómo es posible dentro del aula unir la denominada alta cultura con la tecnocultura para así reflejar información cultural sobre los adolescentes. Este estudio se presenta como una propuesta de innovación aplicable a otros niveles educativos y a otros textos clásicos de la literatura donde la principal característica es el desarrollo de la empatía hacia el otro.

Palabras clave: adolescentes; alta cultura; cultura; información cultural; ficción; tecnocultura.

\section{Abstract}

The present study shows the perception that a group of teenagers between 12 and 13 years old have of themselves and of others. They live in the urban area of Mexico City and are in their first year of secondary education in a private middle-class school. The study has been carried out through 85 memes made after the reading of Alice in Wonderland. This is a quantitative research that shows who are the figures of authority and what are the fears that adolescents have today. It also shows the amount of words that young people need to convey a complete idea through a meme, and their concerns for the social problems they see or have been involved in. All this is discovered through a character or scene selected by the students after reading a universal literature classic assigned in Spanish class. This study seeks to show how it is possible to unite the so-called high culture with technoculture in the classroom to reflect cultural information about adolescents. This study is presented as a proposal for innovation, applicable to other educational levels and to other classic literature texts, where the main characteristic is the development of empathy for others.

Keywords: teenagers; high culture; culture; cultural information; fiction; technoculture.

Cómo referenciar este artículo / How to reference this article:

Marina, N. (2020). Visión de sí y de otros en adolescentes a partir de la elaboración de memes basados en la lectura de ‘Alicia en el país de las maravillas'. Tendencias Pedagógicas, 35, 2020, pp. 118-129 doi: 10.15366/tp2020.35.010 


\section{Introducción}

En México habitan 11.634.031 de preadolescentes y adolescentes de entre 10 y 14 años (INEGI, 2010). De ellos, de acuerdo con la prueba de PISA 2015 de la OCDE, 15 de cada 100 pasan más de seis horas al día conectados a internet, y el $89 \%$ de este tiempo lo invierten dentro de las redes sociales (Asociación de Internet.mx, 2017).

Uno de los pasatiempos favoritos de esta población es la elaboración de memes, los cuales reflejan una forma de percibir e interpretar su realidad, además de información cultural. En este estudio se mostrará cuál es su visión de ellos mismos y de otros, con base en la lectura de un clásico de la literatura: Alicia en el país de las maravillas de Lewis Caroll.

Para esto, se hará la revisión de algunos textos que definirán el significado de cultura para así determinar qué factores de esta se reflejan en la producción de memes. Además, se presenta la elaboración de memes como una posibilidad de unión entre la alta cultura y la tecnocultura, asimismo se muestra la relevancia de la elaboración de estas unidades de comunicación para los adolescentes mexicanos, no solo como forma de entretenimiento, sino como elementos que reflejan la unión de educación, diversión y medio de expresión de la percepción de sí mismos y su realidad.

\subsection{Justificación}

Para la elaboración de este estudio se seleccionó una muestra de 17 alumnos de primero de secundaria pertenecientes a una escuela particular de clase media y media alta en la Ciudad de México, a los cuales la investigadora imparte la clase de Lengua Materna. Cada joven elaboró cinco memes, por lo que la muestra total de análisis fue de 85 .

Las categorías relevantes en este estudio son: ámbito o contexto en el que están relacionados los memes, tipo de estructuras gramaticales empleadas, preocupaciones y figuras de autoridad reflejadas.

El estudio es viable debido a que no existe una investigación previa en nuestro país sobre el tema; sin embargo, entre sus limitaciones se encuentra el tamaño de la muestra seleccionada, ya que representa menos del o.1 \% de la población total de adolescentes y preadolescentes entre 10 y 14 años que habitan en México.

\subsection{Objetivos}

Objetivo general: Determinar cómo los adolescentes reflejan su forma de verse a sí mismos y a los que los rodean a través de la unión de la alta cultura y la tecnocultura, por medio de la elaboración de memes basados en la lectura de la obra Alicia en el país de las maravillas.

Objetivos específicos:

- Mostrar que la elaboración de memes permite reflejar información cultural sobre los adolescentes.

- Comprobar que los adolescentes son los protagonistas como consecuencia del egocentrismo propio de la edad.

- Identificar el tipo de estructuras gramaticales y número de palabras necesarias para elaborar un meme.

- Mostrar las preocupaciones de los adolescentes y sus relaciones con las figuras de autoridad.

\subsection{Pregunta de investigación}

La pregunta de investigación general de este estudio es: ¿será posible deducir parte de la forma de apreciar la realidad vivida y percibida de sí mismos y de otros en los adolescentes a partir de la apropiación de la lectura de una obra literaria en la clase de Español?

\subsection{Hipótesis}

La hipótesis inicial plantea que, efectivamente, los memes son una unidad de comunicación que refleja la realidad vivida y percibida por los adolescentes. Así, se sugieren las siguientes hipótesis secundarias:

Hipótesis 1: Los adolescentes reflejan información cultural a través de la elaboración de memes. Esta, a su vez, mostrará la forma de verse a sí mismos y a los demás. 
Hipótesis 2: Los adolescentes serán los protagonistas de sus memes como reflejo del egocentrismo propio de la edad.

Hipótesis 3. Los adolescentes muestran en los memes sus preocupaciones y la relevancia de las figuras de autoridad presentes en sus vidas.

\section{Estado del arte}

\subsection{Bases que fundamentan la relevancia del tema}

Para comenzar, es necesario definir el término cultura. De acuerdo con Masiá Clavel, en su libro Animal Vulnerable. Curso de antropología filosófica (2015), la cultura abarca un conjunto amplio de comportamientos de la especie humana: maneras de ver e interpretar el mundo; modos de habitar en él y hacerlo habitable, recursos para transformarlo mediante la técnica (p. 65). En la perspectiva etnográfica capta la cultura como el sistema común de vivir de un pueblo.

De acuerdo con Tornos (1965), la cultura es un conjunto de interpretaciones del mundo, compartidas popular y masivamente en la marcha de la vida diaria; interpretación cotidiana de ideas y valores; forma compartida de entender el mundo que se manifiesta en el lenguaje, instituciones y tradiciones; estilos de vida y escalas de valor; la manera particular que tiene un pueblo de servirse de las cosas, de trabajar, de expresarse, de comportarse; formas colectivas de interpretación del mundo por las que se guían las sociedades; código con que la gente descifra los signos en las cosas; esquemas de comprensión de nuestra vivencia cotidiana.

También Masiá Clavel (2015) menciona que:

Se debe revisar los conocimientos adquiridos y las creencias asumidas, con el fin de poder relacionar $\mathrm{y}$ articular ese repertorio del pasado con los nuevos datos y experiencias que van surgiendo. $\mathrm{Al}$ aumentar la experiencia de la vida, se plantea la necesidad de rearticular lo que pensábamos y se piensa qué significa este acontecimiento en la realidad (2015, p. 29).

Es en este punto donde los adolescentes realizan los memes, cuando dan significado a una experiencia a través de una recreación que expresa su forma de ver su realidad a partir de lo vivido, así transmiten información cultural.

De acuerdo con Knobel y Lankshear (2007), los memes son patrones contagiosos de información cultural que se transmiten de mente a mente y que directamente dan forma y propagan acciones clave y modos de pensar de un grupo social. Los memes incluyen melodías populares, frases, ropa, estilos arquitectónicos, formas de hacer cosas, etc. (Knobel y Lankshear, 2007, p. 1).

Para Masiá Clavel (2015) «las suposiciones centrales, conceptos y premisas son más o menos ampliamente compartidas por los miembros de una cultura o subcultura» (p. 29). Al decir «más o menos ampliamente» sugiere una uniformidad en un grupo, la cual permite proveer un sentido de identidad común con el que identificarse, si es que pertenecen al mismo grupo social. Este estudio realizado en una escuela secundaria, perteneciente a la clase media y media alta urbana de la Ciudad de México, permitirá unificar hasta cierto punto la forma de verse a sí mismos y a otros en este sector de la sociedad y entre jóvenes de esta edad.

En cuanto a la importancia de las narrativas, de acuerdo con Rushdie (2018) «el mundo tal vez pueda explicarse mejor en términos de narrativas». Es por esto por lo que se ha decidido plantear la unión de memes y novela en esta investigación. También menciona el hecho de que «cuando leemos un libro que nos gusta, o incluso amamos, nos encontramos de acuerdo con su retrato de la vida humana. Sí, decimos, así es como somos, esto es lo que hacemos los unos con los otros, esto es verdad. Eso, quizás, es donde la literatura puede ayudar más» (Rushdie, 2018). Esta cita nos permite traer a colación dos conceptos que se unen al realizar memes con la lectura de un texto como Alicia en el país de las maravillas: alta cultura y tecnocultura, porque «vivimos en un mundo donde la ciencia y la tecnología forman a la economía global y la cultura diaria» (Benita, 2008). Por un lado, la alta cultura es concebida como «aquella que refleja la autoconciencia de la sociedad y contiene obras de arte, literatura, estudios y filosofía que establecen un marco de referencia compartido entre las personas educadas para su disfrute y aumento de conocimientos» (Scruton, 2012). Alicia en el país de las maravillas es una obra de la alta cultura que la sociedad reconoce como una obra clásica por la trascendencia que ha tenido en diferentes culturas. Por otro lado, está la tecnocultura, que entiende la tecnología como un fenómeno cultural «en la cual se destaca la intersección entre dos esferas: la cultural y la tecnológica» (Hernández y Arciga, 2010). De acuerdo con Carbajal (2015) en su artículo Jóvenes, cultura 
escrita y la tecnocultura, «es la racionalidad propia del funcionamiento y el uso eficaz de todo dispositivo técnico... designa lo aprendido, los usos y el proceso de transformación cognitiva, o sea, la interiorización de los diversos sistemas de saberes necesarios para la puesta en funcionamiento y empleo de las herramientas o de los inventos técnicos» (p. 20).

Es así como la unión de la alta cultura con la tecnocultura a través de la lectura de Alicia en el país de las maravillas permite crear un puente que revela información cultural. A causa de la preferencia que tienen los adolescentes por la elaboración de memes, se consideran la manera más apropiada para investigar una realidad y conocerla, como menciona Clavel $(2015$, p. 23). Las imágenes y textos que se emplean en los memes muestran la cultura de los adolescentes en la sociedad mexicana porque «refleja normas, estrategias, creencias, ideas, valores y mitos transmitidos de generación en generación» (Clavel, 2015, p. 28).

\subsection{Definición del grupo de estudio}

Los jóvenes seleccionados para este estudio se encuentran entre los 12 y los 13 años. Los adolescentes en este rango de edad, por tanto, pertenecen a la denominada generación Z, iGen, iTech, zombies o socratives, de acuerdo con la descripción de Twenge (2017). Se les denomina iGen porque nacieron en la época de internet. Esta generación de jóvenes es la primera que ha estado educada en la sociedad digital: por eso se llama, de acuerdo con Freixe (2005), Generación@. Sin embargo, es muy arriesgado clasificar también a los jóvenes mexicanos dentro de estos estándares creados en la cultura anglosajona, ya que México vive su propia diversidad de culturas, así como de prácticas digitales. Y, además, como menciona Freixe (2005): «factores como el capital cultural o poder adquisitivo tienen más peso que la edad en relación con la capacidad y rapidez con la cual las personas hacen suyas las nuevas tecnologías» (Freixe, 2005, p. 8).

\subsection{Relevancia de los memes en la vida de los adolescentes como forma de comunicación y medio de información}

El concepto «meme» fue aportado por el genetista Richard Dawkins (1976) en su libro The Selfish Gene. Su aproximación a la genética se debe a que los memes son pequeñas unidades de información que, como los genes en la biología, se replican con errores ocasionales y con alguna influencia en sus réplicas.

Analizado desde la psicología, el concepto de meme pone más atención en la toma de decisiones antes de la acción (Aunger, 2002, p. 37), donde la mente es un seleccionador de información, el cerebro se queda solo con lo que considera importante de una situación y puede revelar la organización jerárquica de una cultura (Wilkins \& Gibb, 1998, p. 2).

Para la sociología «la configuración de los memes está informada por, y ayudan a definir y propagar relaciones, acciones o formas de pensar de un grupo social, la probabilidad de que un meme sea contagioso es directa con los valores, creencias y prácticas de un grupo» (Grant 1990, p. 3). También para esta ciencia, revelan la producción cultural y su transmisión.

Para fines de esta investigación conviene realizar un análisis de los memes bajo los comentarios esenciales de la psicología y la sociología. Desde la psicología se retomará la importante acción que realiza el adolescente al seleccionar información reflejando solo lo que es importante para él; y desde la sociología permitirá apreciar la forma de pensar de un grupo social determinado.

Una manera útil de conceptualizar las formas en que los memes se comparten y transmiten dentro y entre grupos es a través de los espacios de afinidad que menciona Gee (2004), que son aquellos espacios interactivos en línea o fuera de línea que comprenden personas unidas libre o estrechamente por medio de actividades compartidas, intereses y objetivos.

\subsection{Razones para la selección de la novela Alicia en el país de las maravillas}

Alicia en el país de las maravillas es un clásico de la literatura fantástica. Fue publicada por primera vez en 1865 y está inspirada en historias que inventó el autor durante un viaje en barco con tres niñas: Charlotte, Alice y Edith. Esta obra forma parte de la denominada «alta cultura» debido a la trascendencia que ha tenido el texto a través de diversas generaciones «y sigue inspirando nuestra imaginación, algo que solo consiguen los grandes clásicos intemporales» (Jiménez, 2015). Sobre la percepción social del libro, Alberto Manguel (2015) en un artículo publicado en el periódico El País con motivo del 150 aniversario de la obra, ha observado 
que «leídos de niño, los libros de Alicia reflejan el asombro y el miedo de la infancia; leídos en la adolescencia, la indignación ante la idiotez e hipocresía de los adultos».

\section{Marco teórico}

Retomando la definición de Masiá Clavel (2015) sobre la cultura, se puede considerar que los memes son un reflejo de la subcultura que representan los adolescentes en México, a través de ellos expresan su modo de habitar en él y al mismo tiempo lo hacen habitable, de acuerdo con las necesidades de su edad. Los memes representan las ideas y valores que rondan su mente y lo manifiestan a través del lenguaje empleado en estas unidades de comunicación.

Siguiendo la misma línea marcada por este autor, es necesario hacer una revisión de los conocimientos adquiridos, es decir, aquellos con los que los adolescentes han sido educados, y a esto se debe añadir la experiencia de la lectura de un libro nuevo para su bagaje cultural. Esto mismo permite que los adolescentes rearticulen lo que pensaban y la elaboración de memes reflejará con qué tipo de lentes lo observan.

Por un lado, se podrá determinar si los memes realizados dentro del grupo seleccionado de adolescentes de 12 y 13 años pertenecientes a la clase media coinciden entre ellos dando una uniformidad de grupo. Por otro lado, es necesario mencionar un elemento característico de la personalidad de los adolescentes: el egocentrismo. «Este se evidencia a través de la existencia de un foco general en sí mismo. El adolescente se encuentra muy centrado en su propia conducta y asume que los otros tienen perspectivas y valores idénticos a los suyos» (Gaete, 2015). Los memes permitirán observar si este egocentrismo se manifiesta y da homogeneidad entre ellos. Debido a las características que poseen los memes, como el uso de imágenes y palabras, podrían considerarse como narrativas, las cuales, de acuerdo con Rushdie (2018), sirven para explicar mejor el mundo que nos rodea, o en este caso, la realidad que viven los adolescentes. La elaboración de memes también se presentará como un método para desarrollar empatía entre el yo adolescente y el otro, reflejado a través de los personajes que aparecen en Alicia en el país de las maravillas.

\section{Método}

La metodología empleada en este estudio fue cuantitativa. Se hizo un análisis de los 85 memes elaborados por los estudiantes y también de los elementos presentes en cada uno de ellos.

El instrumento que se utilizó fue el llenado de la tabla que se muestra en el Anexo A, para cuantificar el número de palabras empleadas, el tipo de imagen, el ámbito al que pertenece y el tipo de humor que emplean.

Tabla 1.

Análisis cuantitativo de memes.

\begin{tabular}{|l|l|l|l|l|l|}
\hline & Meme 1 & Meme 2 & Meme 3 & Meme 4 & Meme 5 \\
\hline Texto & & & & & \\
\hline Número de palabras empleadas & & & & & \\
\hline Imagen (real-ficticia) & & & & & \\
\hline $\begin{array}{l}\text { Ámbito al que pertenece (esco- } \\
\text { lar-hogar-social) }\end{array}$ & & & & & \\
\hline Relación jerárquica que establece & & & & & \\
\hline
\end{tabular}




\begin{tabular}{|l|l|l|l|l|l|}
\hline $\begin{array}{l}\text { Sentido del humor (sarcástico- } \\
\text { divertido-serio) }\end{array}$ & & & & & \\
\hline Capítulo en el que se inspiró & & & & & \\
\hline Personajes que aparecen & & & & & \\
\hline
\end{tabular}

Para realizar este trabajo de campo se asignó la lectura de la obra durante cinco semanas y se publicaron las siguientes instrucciones dentro de la plataforma School Cloud de la institución (Figura 1):

1. Lee los 12 capítulos de la obra.

2. Selecciona cinco personajes o eventos diferentes que suceden en la obra y trasládalos a situaciones de tu vida cotidiana.

Ejemplo: Si eres Alicia, el conejo... es mi mamá porque siempre me está diciendo que se me está haciendo tarde.

3. Elabora cinco memes con base en lo que les sucedió a esos personajes. Puedes utilizar imagechef.com o generadoresdememeonline.com o alguna otra aplicación que tú prefieras. Los memes deben ser entregados impresos en hoja tamaño carta a color con nombre y grupo. Y que tenga un pie de foto que diga:

MEME INSPIRADO EN EL CAPÍTULO

DE LA OBRA ALICIA EN EL PAÍS DE LAS

MARAVILLAS

REPRESENTA PARA MÍ: (Ejemplo: La importancia que tiene la puntualidad)

FECHA DE ENTREGA 15 DE OCTUBRE (O ANTES SI ASÍ LO DESEAS) NO SE RECIBIRÁN TRABAJOS DESPUÉS DE LA FECHA

Revisa el calendario para saber cómo organizar tus tiempos y realizar la lectura de manera individual en casa. Haz los memes conforme te vayas inspirando durante la lectura, no dejes todo para el último momento. El día 16 de octubre se aplicará un pequeño examen escrito sobre la lectura en general. Se prohíbe el uso de faltas de ortografía intencionales dentro de los memes o el uso de anglicismos.

Figura 1.

Imágenes publicadas en School Cloud dando las instrucciones a los alumnos
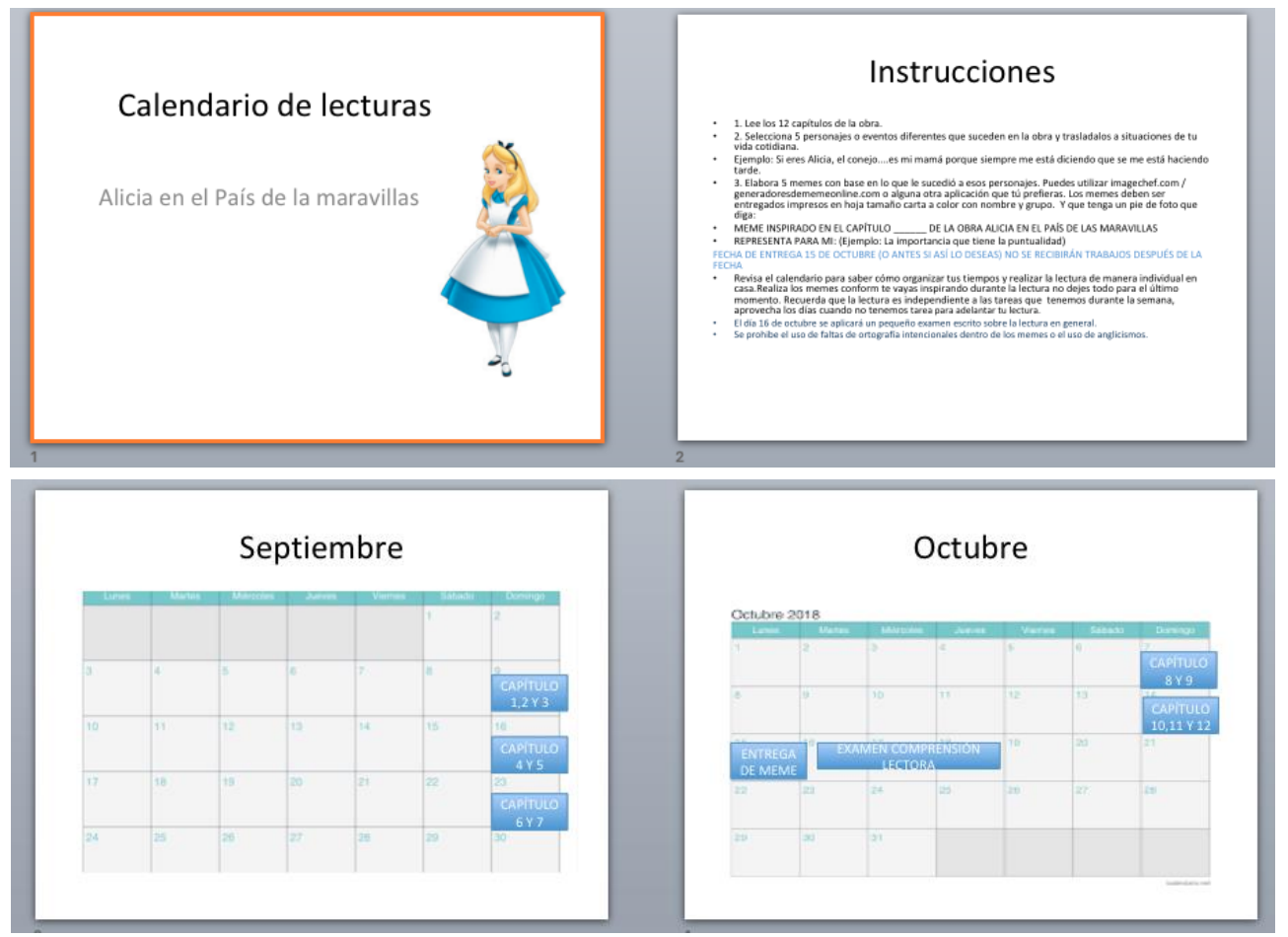


\section{Análisis e interpretación}

Después de la entrega y análisis de los memes se obtuvieron los siguientes resultados:

El promedio de palabras utilizadas en la elaboración de los memes es de 14 palabras por meme. El mínimo de palabras empleadas para expresar una idea es de 2 y el máximo de 43. Así, se pueden apreciar textos como: «Cuando tu mamá te despierta tarde, jya es tarde, ya es tarde!, es hora de irnos ya!»o «Como cuando tu mamá te regaña...». El tipo de estructuras gramaticales empleadas varía desde frases hasta oraciones simples, sin embargo, algunas oraciones no presentan concordancia o coherencia entre sus elementos. Los textos revelan preocupaciones como ser puntuales en la escuela, librarse de un regaño o un desastre natural como un sismo (Figura 2).

Figura 2.

Ejemplo de memes elaborados
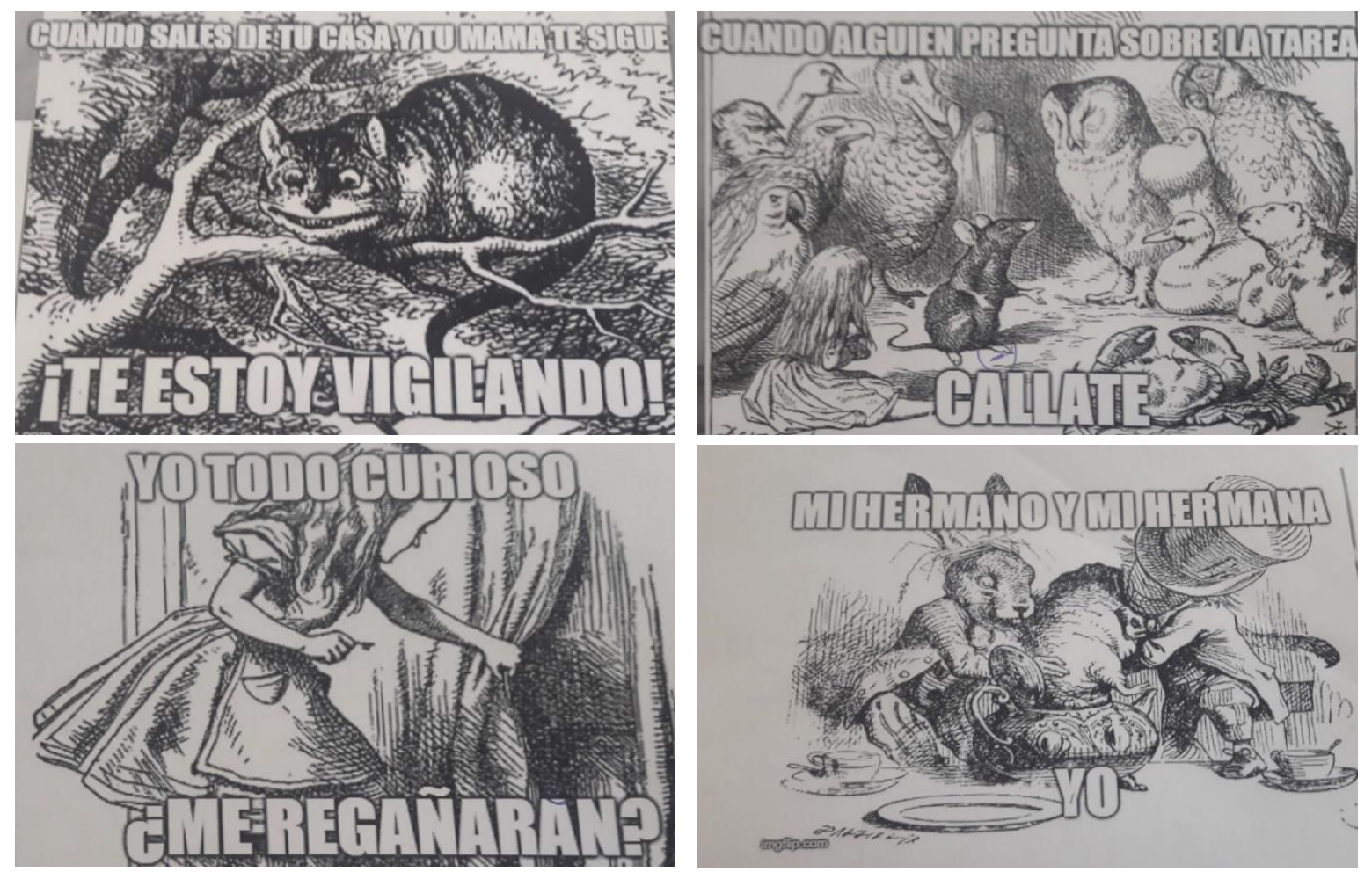

A través de los contextos que se presentan en cada uno de los memes se puede decir que el ámbito al que pertenecen corresponde en su mayoría al personal, con un $34 \%$, seguido del familiar, con un $32 \%$, el escolar, con un $23 \%$ y el social, con un $11 \%$. Esto refleja que los adolescentes muestran en los memes su egocentrismo ya que los dilemas personales o situaciones que les pasan a ellos se ubican en el mayor porcentaje, seguidos del ambiente familiar y el escolar (Figura 3).

Figura 3.

Ambitos mencionados por los adolescentes en la elaboración de memes

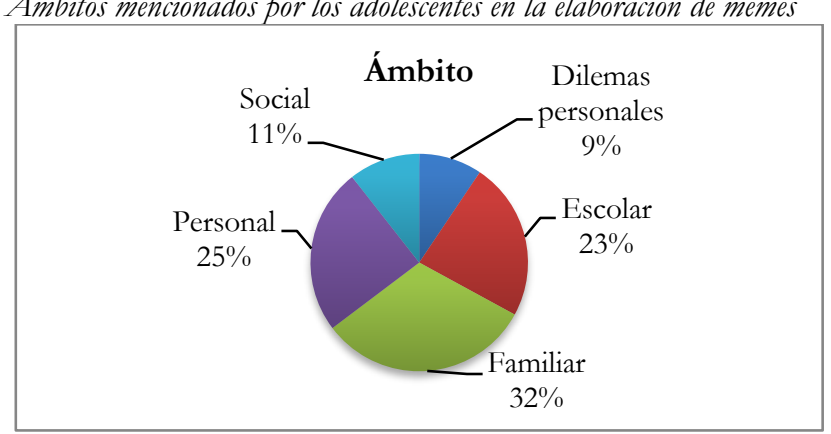


En cuanto a las relaciones jerárquicas establecidas, se revela que el $21 \%$ de los adolescentes estudiados muestran a su mamá como la mayor influencia en casa; el $9 \%$ considera a los maestros como una autoridad; el $5 \%$ considera a los hermanos como una autoridad de mando; el $5 \%$ considera al papá en este mismo rubro; otro $5 \%$ considera a sus propios amigos como figuras de dominio y el $3 \%$ percibe que la familia en general tiene cierto poder sobre él. El 52 \% restante no menciona ninguna relación jerárquica (Figura 4). Así, se puede mostrar que la mayor figura de autoridad presente en los adolescentes es la madre, seguida por el maestro, sin embargo, llama la atención que el $52 \%$ de los estudiantes no hayan mencionado a ninguna autoridad. Se puede decir que la figura de autoridad toma menor relevancia en la vida de los adolescentes y no es una prioridad ubicarla dentro de su visión de la realidad. En este momento de la vida los adolescentes procuran presentar una actitud rebelde frente a los mayores.

Figura 4.

Relaciones jerárquicas seleccionadas por los adolescentes

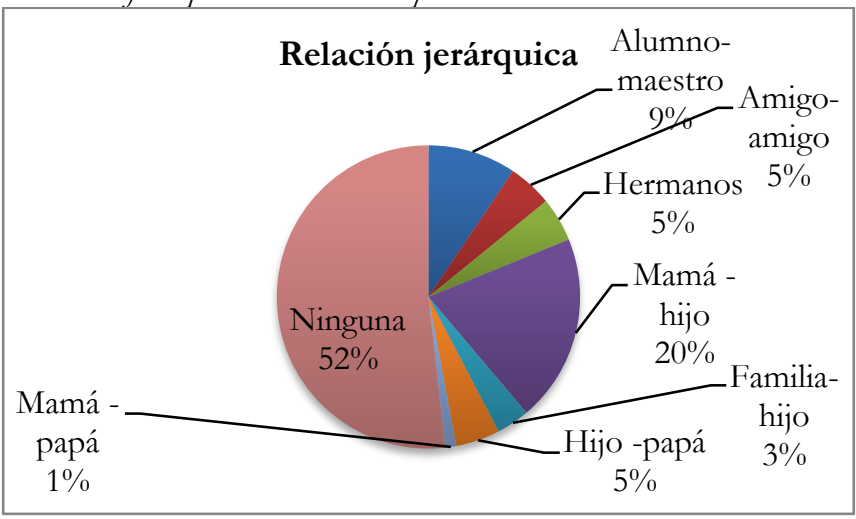

En cuanto al sentido del humor (Figura 5), el $66 \%$ de los memes manifiestan un humor blanco divertido; el $13 \%$ presentan un humor sarcástico; el $11 \%$ tienen un tono dramático y el $8 \%$ exhibe alguna queja familiar. Así, se tienen memes con frases como: «Como cuando tu mamá te regaña por hacer llorar a tu hermano, y contestas: pero yo no hice nada». Los adolescentes se muestran al mundo siendo capaces de reírse de sí mismos, presentando situaciones divertidas.

Figura 5.

Sentido del humor empleado dentro de los memes

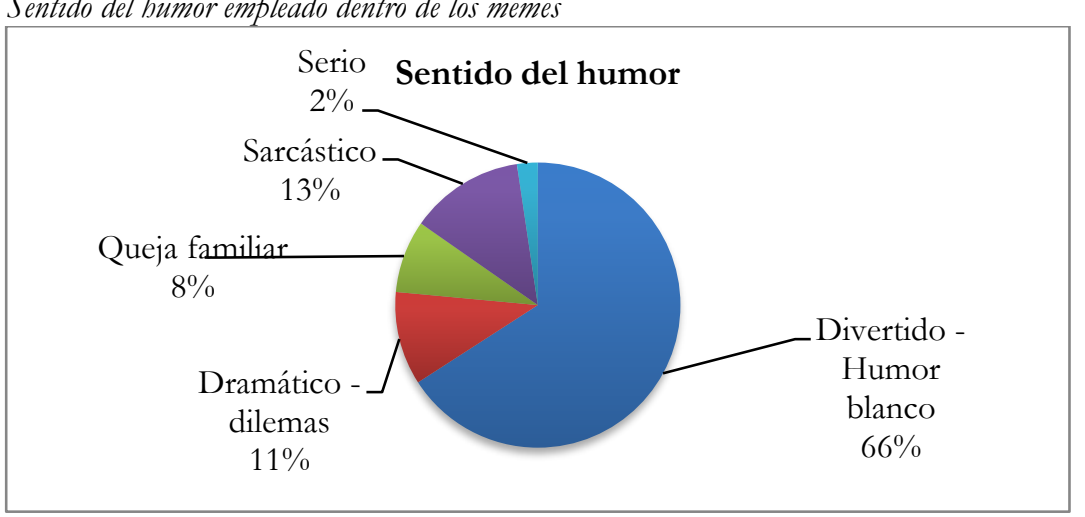

Los capítulos que representan mayor inspiración para la elaboración de memes son: el número 12, La declaración de Alicia, con el $18 \%$; el 11, ¿Quién robó las tartas?, con el $15 \%$; el 10, La cuadrilla de las langostas, con el $13 \%$; el 9, Historia de la falsa tortuga, con el $12 \%$ y el 8, El croquet de la reina, con el $10 \%$. El capítulo preferido por los adolescentes desnuda cierta rebeldía al desarrollo, el miedo a convertirse en adultos y adquirir nuevas responsabilidades, revela que aún mantienen cierto amor y extrañan la infancia ya que se menciona «la muchacha imaginó que aquella misma hermana pequeña se convertiría en una mujer, a través de sus años de madurez y su corazón simple y amor de la infancia reuniría a su alrededor a otros niños que le harían recordar su propia niñez y los felices días de verano» (Carroll, p. 190) 
Referente a los personajes principales que aparecen, la Figura 6 muestra que el $51 \%$ presenta a Alicia, a quien utilizan como reflejo de sí mismos, seguida por el Conejo (19\%), la Reina de Corazones (7\%), el Gato $(6 \%)$ y el Sombrerero (5\%). Entre los otros personajes que aparecen se encuentran el soldado naipe, la rata, el lacayo rana, la duquesa y los animales del bosque. Cabe destacar que Alicia los representa a ellos mismos dentro de los memes, ellos se ven reflejados como Alicia y ven a los demás personajes como sus padres, hermanos, amigos o maestros.

Figura 6.

Personajes principales seleccionados por los adolescentes

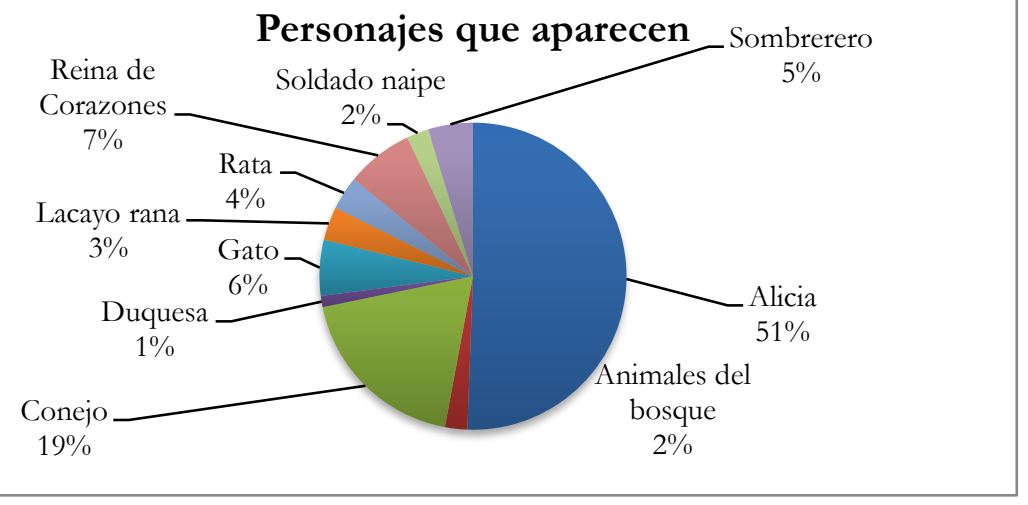

Como personajes secundarios, el $18 \%$ presenta al Sombrerero, el $14 \%$ a la Reina de Corazones, el $14 \%$ a los animales del bosque y el $11 \%$ a la oruga y el conejo. Entre otros, aparecen los reyes y la rata (Figura 7).

Figura 7.

Personajes secundarios seleccionados por los adolescentes

\section{Personajes secundarios}

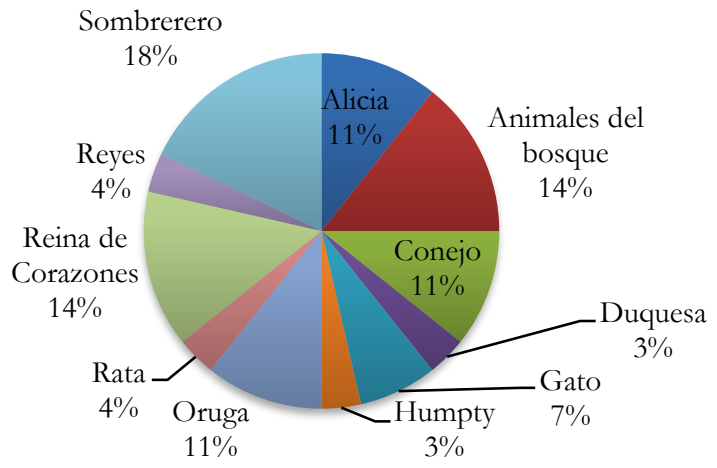

Respecto a las hipótesis planteadas, y con base en los resultados obtenidos, se puede afirmar que la elaboración de memes basados en literatura refleja la realidad que viven y perciben los adolescentes.

Efectivamente, se comprobó que los adolescentes reflejan información cultural a través de la elaboración de memes, tal como: la percepción de sí mismos como el centro de atención, el reflejo de la importancia de las jerarquías y la nula necesidad de presentar estructuras gramaticales completas para poder expresar una idea.

De acuerdo con los modelos de pensamiento propuestos por Masiá Clavel (2015), los adolescentes reflejan realizar los memes «de afuera hacia adentro, se ponen de pie para percibir al mundo, a los acontecimientos» (p. 82) y desde ahí lo interpretan.

Durante la lectura del texto clásico, como menciona Masiá (2015), se buscó «el arte de leer e interpretar la vida humana... mediante el diálogo con personas de identidades diferentes» (p. 83), en este caso los personajes mismos de Alicia en el país de las maravillas. 


\section{Conclusiones}

Después del análisis de los 85 memes elaborados por los adolescentes se puede concluir que los memes en la adolescencia se manifiestan, como menciona Tornos (1992), como un «código con que la gente descifra los signos en las cosas». La elaboración de memes a partir de la lectura de una obra de la literatura clásica puede ser el punto donde se unen la alta cultura con la tecnocultura, reflejando información cultural.

La información cultural que se descubrió después de la investigación es la siguiente: la cantidad de palabras que necesitan para elaborar un meme es variada, sin embargo, dos palabras pueden ser suficientes para expresar y comentar una realidad. Los adolescentes reflejan su egocentrismo al contextualizar la mayoría de los memes en situaciones y dilemas personales que solo les atañen a ellos.

En cuanto a las figuras de autoridad presentes en su vida, la que mayor jerarquía tiene es la madre, seguida por el maestro; sin embargo, destaca que algunos adolescentes prefieren omitirlas, esto podría percibirse como resultado del egocentrismo y cierta rebeldía manifestada en esta época de la vida.

Referente al humor que utilizan en los memes, los adolescentes poseen una personalidad divertida e inocente, son capaces de reírse de situaciones de su vida a través de los personajes de Alicia, que les permiten esconderse detrás de ellos para no caer en ridículo ante la audiencia. Para ellos es divertido reírse de sí mismos, pero a través de otros.

Los adolescentes reflejan, a través del capítulo favorito seleccionado, que tienen cierto miedo a crecer y dejar de ser niños. El personaje que más se menciona es Alicia, quien los representa en la mayoría de los memes. A través de ella logran proyectar ciertas situaciones que les preocupan como: ser puntuales en la escuela, librarse de un regaño de sus papás o maestros, o un desastre natural como un sismo. Cabe destacar que la Ciudad de México tuvo un sismo de 7.1 grados el 19 de septiembre de 2017, que dejó marcada a esta generación de jóvenes, por lo que un evento natural de ese tipo se encuentra entre sus preocupaciones.

El tamaño de la muestra es muy pequeña para asegurar que nos encontramos frente a una tendencia, sin embargo, sirve como base para un estudio más amplio que se puede trasladar a otras obras literarias. Asimismo, esta investigación permite definir a los memes no solo como forma de entretenimiento, sino como elementos que reflejan la unión de educación, diversión y medio de expresión de la percepción de su realidad y de la visión de sí mismos. De esta manera, y al unir alta cultura con cultura a través de la elaboración de memes que revelan información cultural, se propone el esquema de la Figura 8.

Figura 8.

Información cultural a través de memes

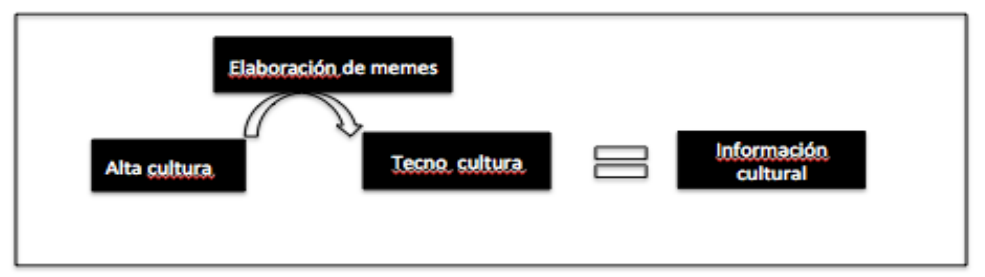

Queda este trabajo de investigación como una pauta para futuros análisis en los cuales la alta cultura se una con la tecnocultura y se pueda realizar la reinterpretación de otros clásicos de la literatura a partir de una tendencia que refleja parte de la cultura digital de los adolescentes.

\section{Agradecimientos}

El presente artículo fue redactado bajo la supervisión y guía de la Dra. Paola Ricaurte, Dra. Margo Echenberg y Dr. Osmar Sánchez, quienes con sus constantes lecturas y comentarios se apasionaron junto conmigo 
en el análisis de los memes de los adolescentes. Y a mi compañera de camino durante el doctorado, la Mtra. Adelina Pérez, con quien comparto la pasión por la enseñanza.

\section{Anexo A. Análisis de memes}

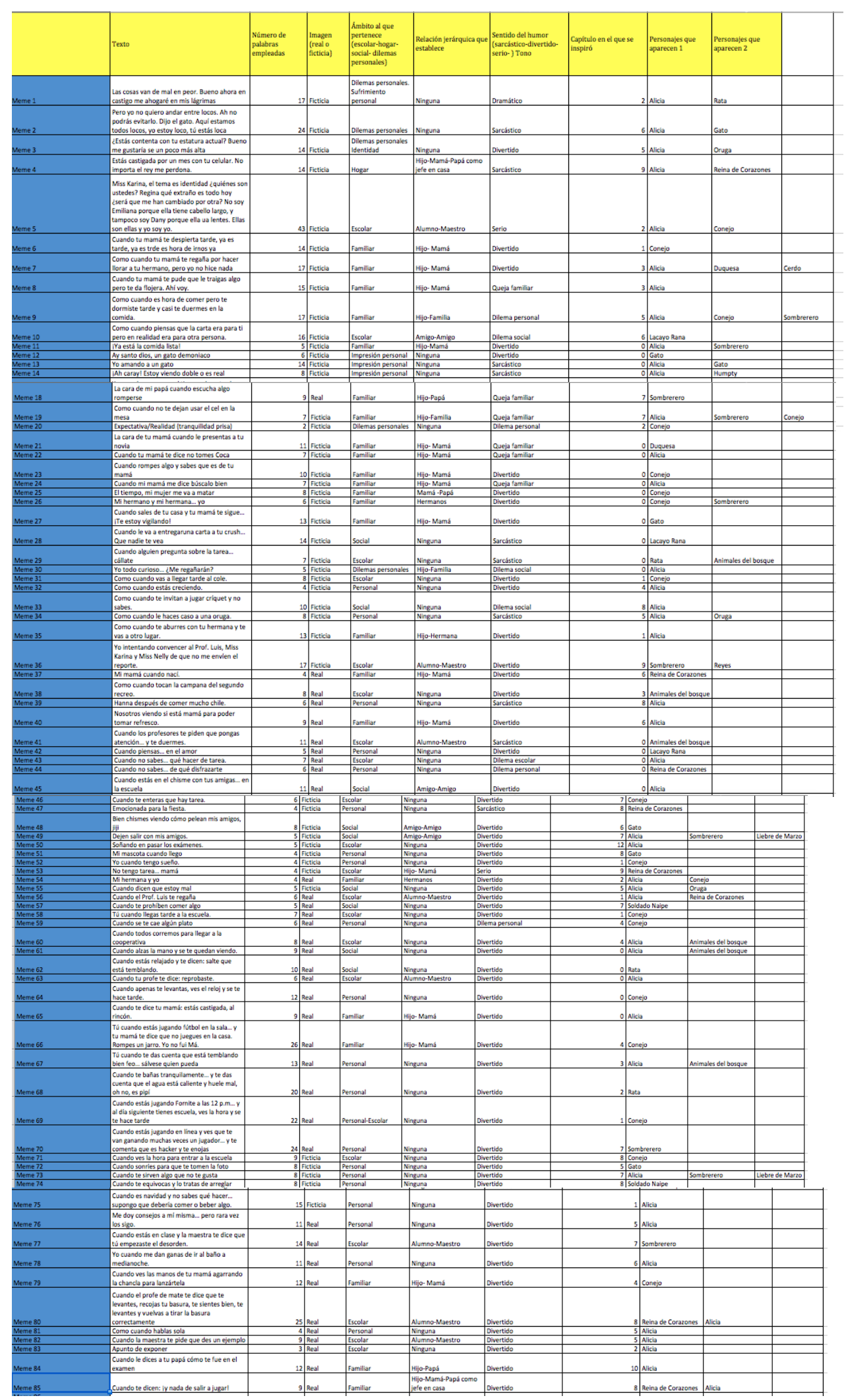




\section{Referencias}

Asociación Mexicana de Internet (2017). Reporte: Hábitos de usuarios de internet México 2017. Recuperado de https://strategia20.com/reporte-habitos-de-usuarios-de-internet-mexico-2017.

Aunger, R. (2002). The Electric Meme. New York: Simon and Schuster.

Benita, D. (2008). Technoculture: The Key Concepts Debra Benita Shaw. Berg Publishers. United States.

Carvajal, G. (2005). Jóvenes, cultura escrita y tecnocultura. Madrid: Anagrama.

Dawkins, R. (1976). The Selfish Gene. New York: Oxford University Press.

Freixa, C. (2005). La habitación de los adolescentes en Papeles del CEIC, no.16, CEIC (Centro de Estudios sobre la Identidad Colectiva), Universidad del País Vasco, http://www.ehu.eus/CEIC/papeles/16.pdf.

Gaete, V. (2015). Desarrollo psicosocial del adolescente. Revista cbilena de pediatría, 86(6). doi: 10.1016/j.rchipe.2015.07.005

Gee, P. (2004). Lo que nos enseñan los videojuegos sobre el aprendiraje y el alfabetismo. Málaga: Ediciones Aljibe.

Grant, G. (1990). Memes: Introduction Principia Cybernetica. Recuperado de http://pespmc1.vub.ac.be/MEMIN.html.

Hernández, M. \& Arciga, B. (2010). Tecnologias culturales, entornos comunicacionales y la reconfiguración del sujeto. Sintética. No. 34. Enero-junio. Tlaquepaque.

INEGI (2011). Censo de Población y Vivienda 2010. Resultados definitivos, México.

Jiménez, J. (2015). Alicia, 150 años en el País de las Maravillas. Corporación de Radio y Televisión Española. Recuperado de http://www.rtve.es/noticias/20150523/alicia150-anos-pais-maravillas/1148517.shtml

Knobel, M., \& Lankshear, C. (2007). Online memes, affinities, and cultural production. En $A$ new literacies sampler. New York: Peter Lang. Recuperado de http://liteacyandtech.pbworks.com/f/Text.pdf.

Lewis, C. (1865). Alicia en el País de las Maravillas. Edición 2017. Madrid: Vicens Vives.

Masiá, J. (2015). Animal vulnerable. Madrid: Trotta.

Manguel, A. (2015). Alicia cumple 150 años. Análisis, Recuperado de https://elpais.com/cultura/2015/05/23/actualidad/1432400906_608763.html.

OCDE (2016). PISA 2015 Assessment and Analytical Framework: Science, Reading, Mathematic and Financial Literacy. Paris: OECD Publishing. doi: 10.1787/9789264255425-en

Rushdie, S. (2018). Truth, Lies and Literature. The New Yorker. Recuperado de https://www.newyorker.com/culture/cultural-comment/truth-lies-and-literature.

Scruton, R. (2012). High culture is being corrupted by a culture of fakes. The Guardian. Recuperado de https://www.theguardian.com/commentisfree/2012/dec/19/high-culture-fake.

Tornos, A. (1965). Antropología filosófica. Barcelona: Salvat.

Twenge, J. M. (2017). iGen: Why today's super-connected kids are growing up less rebellious, more tolerant, less happy-and completely unprepared for adulthood (and what this means for the rest of us). New York: Atria Books.

Wilkins, A. \& Gibb, W. (1998). Toward Culturally Sensitive Theories of Culture Change. The Academy of Management Review, 13(4). doi: 10.5465/amr.1988.4307391 